\title{
Multistep signaling requirements for pituitary organogenesis in vivo
}

\author{
Mathias Treier, ${ }^{1}$ Anatoli S. Gleiberman,, ${ }^{1,2,5}$ Shawn M. O'Connell, ${ }^{1,5}$ Daniel P. Szeto, ${ }^{1,3}$ \\ Jill A. McMahon, ${ }^{4}$ Andrew P. McMahon, ${ }^{4}$ and Michael G. Rosenfel $d^{1,6}$ \\ ${ }^{1}$ Howard Hughes Medical Institute, ${ }^{2}$ Eukaryotic Regulatory Biology Program, ${ }^{3}$ Biomedical Sciences Graduate Program, \\ University of California, San Diego, School and Department of M edicine, La Jolla, California 92093-0648 USA; ${ }^{4}$ The Biolabs, \\ Harvard University, Cambridge, M assachusetts 02138 USA
}

\begin{abstract}
During development of the mammalian pituitary gland specific hormone-producing cell types, critical in maintaining homeostasis, emerge in a spatially and temporally specific fashion from an ectodermal primordium. We have investigated the molecular basis of generating diverse pituitary cell phenotypes from a common precursor, providing in vivo and in vitro evidence that their development involves three sequential phases of signaling events and the action of a gradient at an ectodermal boundary. In the first phase, the BMP4 signal from the ventral diencephalon, expressing BMP4, Wnt5a, and FG F8, represents a critical dorsal neuroepithelial signal for pituitary orgen commitment in vivo. Subsequently, a BMP2 signal emanates from a ventral pituitary organizing center that forms at the boundary of a region of ord ectoderm in which Shh expression is selectively excluded. This BMP2 signal together with a dorsal FGF8 signal, appears to create opposing activity gradients that are suggested to generate overlapping patterns of specific transcription factors underlying cell lineage specification events, whereas Wnt4 is needed for the expansion of ventral pituitary cell phenotypes. In the third phase, temporally specific loss of the BMP2 signal is required to allow terminal differentiation. The consequence of these sequential organ and cellular determination events is that each of the hormone-producing pituitary cell types-gonadotropes, thyrotropes, somatotropes, lactotropes, corticotropes, and melanotropes-appear to be determined, in a ventral-to-dorsal gradient, respectively.
\end{abstract}

[Key Words: Pituitary; organogenesis; cell phenotype; transcription factor; BMP; FGF; Wnt]

Received March 23, 1998; revised version accepted A pril 21, 1998.

The anterior pituitary gland exerts its pivotal roles in homeostatic regulation of vertebrates by signaling to peripheral organs, such as the adrenal gland and thyroid gland under control of the endocrine hypothalamus (for review, see Treier and Rosenfeld 1996). The mature gland contains six hormone-producing cell types, including corticotropes secreting adrenocorticotropin (ACTH); melanotropes secreting melanocyte-stimulating hormone (M SH); thyrotropes secreting thyroid-stimulating hormone (TSH); gondadotropes secreting luteini zing hormone ( $\mathrm{LH})$ and follicle-stimulating hormone (FSH); somatotropes secreting growth hormone $(\mathrm{GH})$; and lactotropes secreting prolactin. FSH, LH, and TSH are heterodimeric peptide hormones that share a common subunit referred to as $\alpha$-glycoprotein subunit $\alpha \mathrm{GSU}$ (for review, see Voss and Rosenfeld 1992). These cell types emerge from a common primordium in a precise spatial and temporal pattern (Simmons et al. 1990; Japon et al . 1994); because of the well-defined nature of these cell types the pituitary gland has provided an excellent

\footnotetext{
${ }^{5}$ These authors contributed equally to this work. ${ }^{6} \mathrm{C}$ orresponding author.

E-MAIL mrosenfeld@ucsd.edu; FAX (619) 534-8180.
}

model system in which to investigate the molecular mechanisms that underl ie the appearance of distinct cell phenotypes during mammalian organogenesis.

The anterior pituitary gl and arises as a midline structure from the anterior neural ridge immediately anterior to the adjacent region of the neural plate from which the hypothalamus and posterior pituitary will develop (Couly and Le Dourain 1988; Eagelson and Harris 1990). A number of transcription factors are expressed in the area of the pituitary primordium including Six-3 (Oliver et al. 1995), PAX-6 (Walther and Gruss 1991), and Rpx/ Hesx1 (Thomas et al. 1995; Hermesz et al. 1996), all of which continue their expression in the oral ectodermal field and in Rathke's pouch, which first appears as an invagination of the oral ectoderm, making direct cellcell contact with the neuroepithelium of the nascent diencephalon at embryonic days 8.5-9.0 (E8.5-9.0) in mouse development (Jacobsen et al. 1979). Concurrent with organ commitment, a LIM-homeodomain factor, Lhx3 (Zhadanov et al. 1995), al so referred to as P-Lim (Bach et al. 1995), is expressed in a fashion restricted to Rathke's pouch, as well as the related factor Lhx4 (Sheng et al. 1997). Deletion of the Lhx-3/P-Lim gene in mice results in failure of the pituitary gland to grow and differentiate, al though Rathke's pouch forms (Sheng et al. 
1996), whereas a double gene del etion for both Lhx3 and Lhx4 results in failure in formation of Rathke's pouch (Sheng et al. 1997). The OTX related factor Ptx1/P-OTX (Lamonerie et al . 1996; Szeto et al . 1996) is al so expressed throughout early pituitary development, whereas a nuclear receptor, SF1, appears to be expressed later in the nascent gonadotrope lineage (Luo et al. 1994). A tissuespecific POU domain factor Pit-1 is required for terminal differentiation, growth, and survival of somatotropes, lactotropes, and thyrotropes (Li et al. 1990) and is expressed ventrally on E13.5 in the caudomedial region of the nascent gl and that will express growth hormone, prolactin, and $\mathrm{TSH} \beta$, with thyrotropes being the most ventral of the three Pit-1 producing cell types (Simmons et al. 1990; Japon et al. 1994). In addition, a paired-like homeodomain factor Prop-1 proved to be required for determination of the Pit-1 lineage (Sornson et al. 1996). Whereas these studies have begun to el uci date the transcription factors responsible for critical aspects of pituitary gland development, the extracellular signals that dictate the serial events required for pituitary organogenesis remain undefined.

The appl icati on of genetic approaches to development, initially in Drosophila, led to discovery of both transcription factors and the signaling molecules Decapentapl egic (Dpp), Wingless (Wg), and Hedgehog ( $\mathrm{Hh}$ ) critical for initial pattern formation, including dorsal and ventral patterning (for review, see Rusch and Levine 1996), and later development of numerous systems and structures derived from imaginal discs (for review, see Lawrence and Struhl 1996). The subsequent identification and study of their mammalian orthologs revealed a large family of bone morphogenetic proteins (BM Ps), Wnt, and $\mathrm{Hh}$ molecules. Their potential roles in mammalian development and organogenesis has received intensive attention in the past few years, with evidence of their involvement in several models including limb (for review, see Johnson and Tabin 1997), spinal cord (for review, see Tanabe and Jessell 1996), and tooth development (for review, see Thesl eff and Sharpe 1997), as well as in somite patterning (for review, see Bumcrot and M cM ahon 1995). Similarly, roles for the large family of fibroblast growth factors (FGFs) in early mammalian development and in organogenesis have been suggested (for review, see Tabin 1995).

In this paper we have used several experimental approaches to understand the serial signaling events that might underlie the process of pituitary development from initial organ commitment to the appearance of mature cell phenotypes. We report that BMP4, Wnt5a, and FGF8 are expressed in distinct, overlapping patterns in the ventral diencephalon, whereas Shh, initially expressed uniformly in the oral ectoderm, is excluded from the developing Rathke's pouch, creating a molecular boundary within the continuous ectoderm from which a ventral-to-dorsal gradient of BM P2 arises. We provide in vivo and in vitro evidence that BM P4 is required for the first phase of development-organ commitment of the pituitary gland, whereas the subsequent generation of opposing ventrodorsal BMP2/FGF8 gradients serve to dictate the second phase-determination of ventral cell phenotypes (gonadotropes and the Pit-1 lineage) and dorsal phenotypes (mel anotropes and corticotropes), respectively. Finally, attenuation of the BM P2 signal is shown in vivo to be required for terminal differentiation of ventral cell types, the third phase of organogenesis. Thus, the well-described nature of the specific cell phenotypes within the pituitary gland have permitted interpretation of our in vivo experiments to propose a model for multistep signaling regulation of pituitary organogenesis.

\section{Results}

Signaling molecules in pituitary organogenesis

We initiated our investigation of early pituitary organogenesis by del ineating the expression of potential signaling molecules in the neuroepithelium and subsequently the pituitary gland and/or surrounding mesenchyme, evaluating known members of the BMP, FGF, and Wnt gene families (Hogan 1996; Cadigan and Nusse 1997). BMP4 (Jones et al. 1991) and FGF8 (Crossley and M artin 1995), reported to be expressed in the infundibulum at E10.5, were found to be expressed in the ventral diencephalon during the initial development of Rathke's pouch and subsequently in the infundibulum until emergence of specific cell lineages, with initial BMP4 expression detected temporally prior to the appearance of FGF8 (Fig. 1; data not shown). In addition, Wnt5a was found to be expressed throughout the di encephal on (Fig. 1), exhibiting a less restricted expression than BMP4 and FGF8. Wnt4 expression is also detected in Rathke's pouch and is sustained later dorsally and ventrally through E14.5. The oral ectoderm appears to uniformingly express Shh; with the morphological appearance of Rathke's pouch, Sonic hedgehog (Shh) expression was restricted out of the invagi nating oral ectoderm, remaining expressed in the surrounding oral ectoderm until at least E11, and thus represents a molecular boundary at the morphological transition between the oral ectoderm and Rathke's pouch (Fig. 1; data not shown). Because this pattern is reminiscent of the anterior-posterior compartment boundary in the Drosophila wing (Basler and Struhl 1994) in which Hh in posterior cells locally induces expression of Dpp in adjacent anterior cells, we investigated whether there might be similar induction of the expression of the Dpp counterparts, BMP2 or BMP4, in the adjacent Shh-nonexpressing cells of the nascent Rathke's pouch. We found that initial expression of BMP2 was observed at the oral ectoderm/Rathke's pouch boundary on E10.5 within Rathke's pouch ectoderm and with expression in the adjacent mesenchyme; by E12.0 expression was continuous throughout Rathke's pouch and in the underlying, condensing mesenchyme with attenuation of the signal by E13.5-14. These data were consistent with the possibility that a ventral BMP2 signal might be essential for the development of specific pituitary cell lineages. Furthermore, we found that one of the known BM P antagonists, chordin (Piccolo et al. 1996), is expressed in the mesenchyme caudal to the developing anterior pituitary gland. 


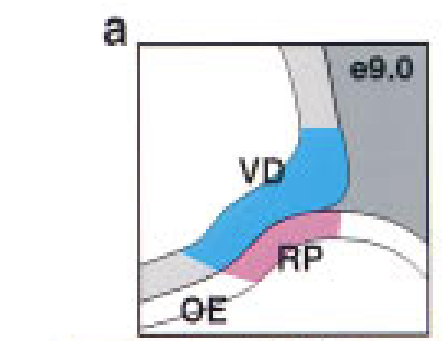

b
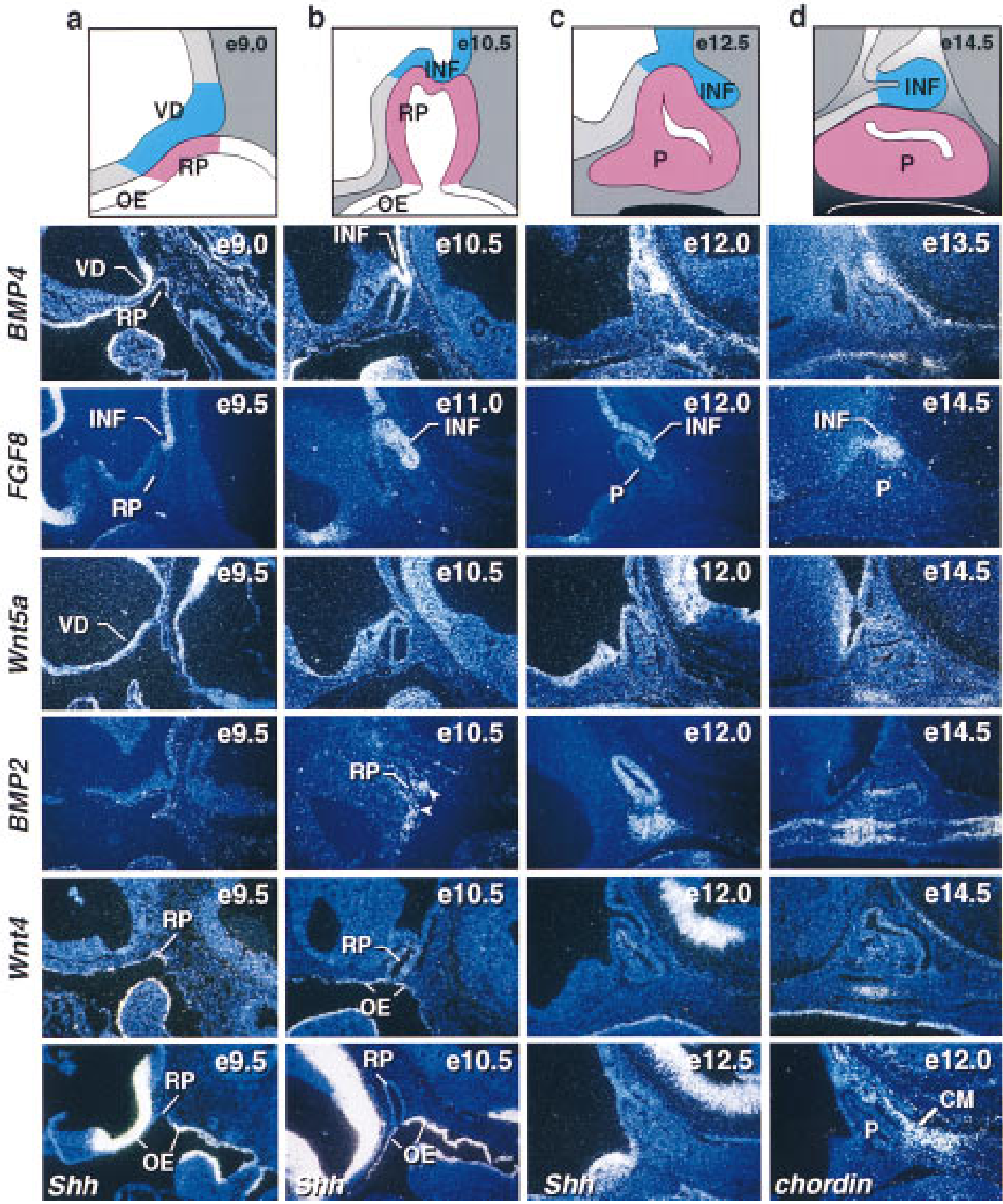

Figure 1. Expression of signaling molecules during early stages of pituitary devel opment. Schematic representation of different stages of pituitary devel opment (a-d). In situ hybridization analysis for BMP4, FGF8, Wnt5a, BMP2, Wnt4, Sonic hedgehog (Shh), and chordin during early stages of pituitary development [embryonic day (e) of mouse development is indicated at top right of each panel ]. BMP4 expression is detected early on in the ventral diencephal on and later in the infundibulum to subsequently disappear. FGF8 is expressed temporally later than BMP4 in the infundibulum. Wnt5a is expressed throughout the ventral diencephal on not showing any restriction. No BMP2 expression is detected early in the vicinity of Rathke's pouch. At E10.5 BMP2 expression was detected in the most ventral part of Rathke's pouch ectoderm and in some adjacent mesenchymal cells (arrows). By E12.0 BMP2 was expressed throughout Rathke's pouch and in the underlying condensing mesenchymal cells. Two days later BMP2 expression is confined to the perilumenal cells in Rathke's pouch and the underlying cartilage growth zone. Wnt4 expression is observed in the oral ectoderm and Rathke's pouch throughout pituitary gland development. Shh expression is observed throughout the oral ectoderm, whereas the invaginating part of oral ectoderm that becomes Rathke's pouch is void of any detectable expression, creating a molecular boundary between two ectodermal domains of Shh expressing and nonexpressing cells. The BM P antagonist chordin is expressed in the caudal mesenchyme (CM) adjacent to Rathke's pouch. BMP2 and Wnt4 expression is noted in the condensing mesenchyme beginning at E12. (INF) infundibulum; (RP) Rathke's pouch; (OE) oral ectoderm; (P) pituitary; (VD) ventral diencephal on. 
In vitro requirement for ventral diencephal on in pituitary development

To further investigate the role of the ventral diencephaIon in Rathke's pouch development, we established a ventral diencephalon/Rathke's pouch organ coculture system. Isolation and culturing of Rathke's pouch explants from E9.5 embryos required cocultivation with ventral diencephal on from the same stage to achieve ACTH, Pit-1, and $\alpha$ GSU cell phenotypes (Fig. 2Aa,e,i); coculturing under identical conditions with COS cells could not replace this activity (Fig. 2Ac,g,k); only few ACTH-positive cells were detectable (Fig. 2Ac). In contrast, Rathke's pouch cell explants from E10.5 embryos were capable of generating ACTH, Pit-1, and $\alpha \mathrm{GSU}$ cell lineages, whether cultured in the presence or in the absence of the ventral diencephal on (Fig. 2Ab,d,f,h,j,l). These results imply that at $\sim \mathrm{E} 10.5$, the pituitary gland switches from an extrinsic (ventral diencephal on) to intrinsic (Rathke's pouch) signaling mode that is required for cell lineage specification.

To investi gate whether BM P4 or Wnt5a activity al one or together was sufficient to induce the $\alpha$-glycoprotein subunit ( $\alpha$ GSU) in E9.5 Rathke's pouch explants, we cultured E9.5 Rathke's pouch explants together with COS cells that were transfected with cytomegal ovi rus (CMV)based expression vectors containing BMP4, Wnt5a, Shh, or FGF8 CDNAs, alone or in all possible dual combinations. Whereas BM P4, or to a lesser extend Wnt5a alone were only sporadically able to induce $\alpha \mathrm{GSU}$ in the coculture system (Fig. 2Bf,g); the combination of BMP4 with Wnt5a was able to consistently induce robust expression of $\alpha \mathrm{GSU}$ in these explants (Fig. 2B h). However, the coculture system proved unable to faithfully reproduce all aspects of later temporal events in pituitary development. For example, few TSH $\beta$-producing cells were
A

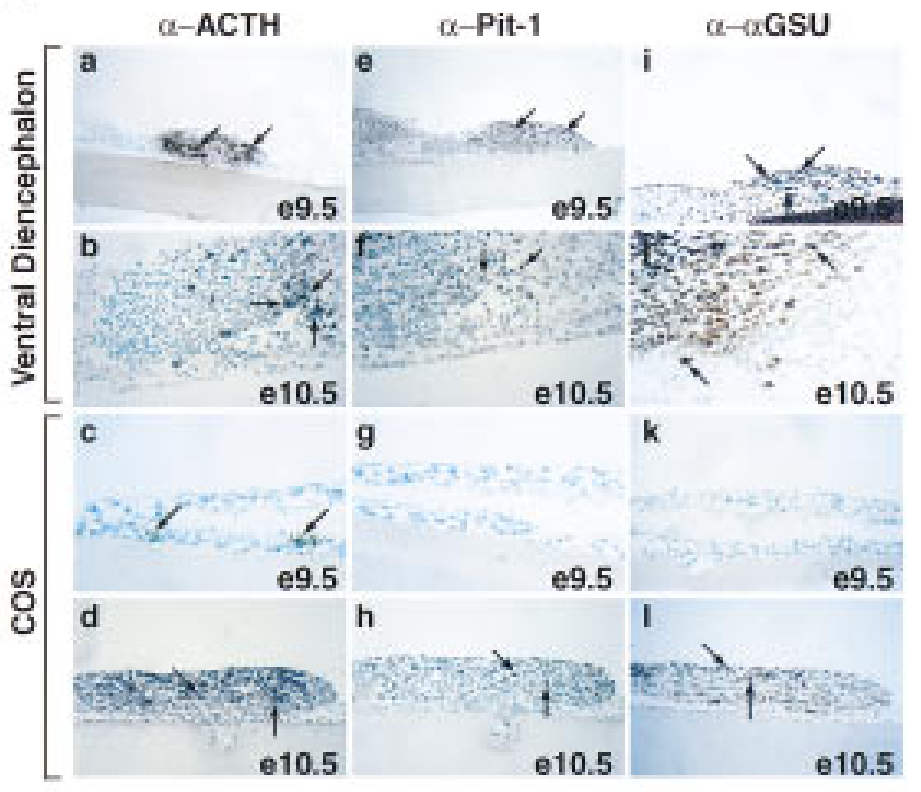

B

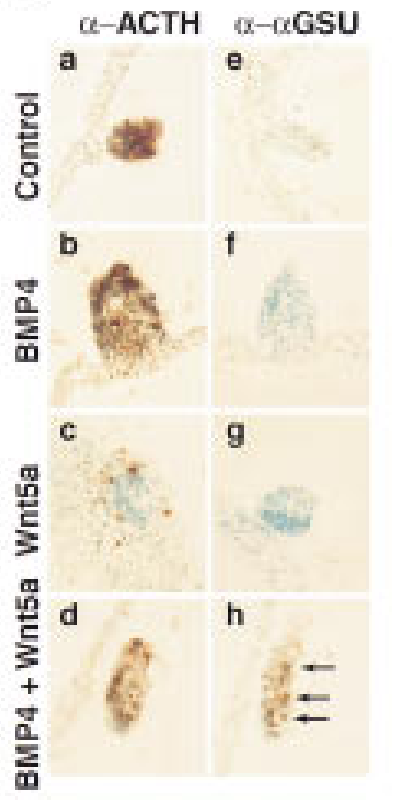

C

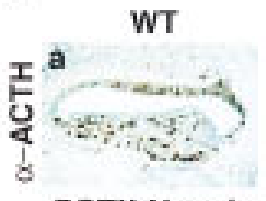

POTX-Noggin

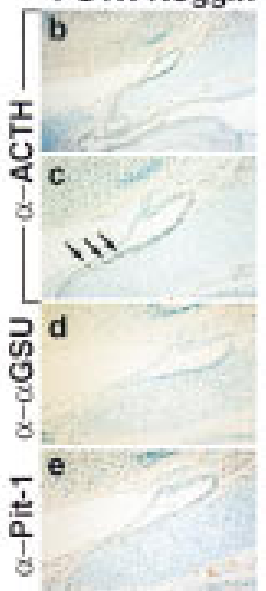

Figure 2. BM P activity is required for anterior pituitary development. (A) Requirement for signaling from the ventral diencephal on in the induction of pituitary lineages. (a,e,i) Coculturing of E9.5 ventral diencephal on with E9.5 Rathke's pouch explant for 6 days resulted in the appearance of all major lineages as shown by immunohistochemical staining with ACTH (a), Pit-1 (e), and $\alpha$ GSU (i) antisera. $(b, f, j)$ Coculturing experiments done under the same conditions with explants from E10.5, respectively, resulted in the same outcome as in a,e, and i). (c,g,k) Coculturing E9.5 Rathke's pouch explants in the presence of COS cells for 6 days led to the appearance of only few ACTH-positive cells (arrows, c), no Pit-1 and $\alpha$ GSU-positive cells were detected (g,k). (d,h,l) Coculturing experiment done under the same conditions as under (c,g,and k) with Rathke's pouch explants from E10.5, resulting in the appearance of ACTH (d)-, Pit-1 (h)-, and $\alpha$ GSU (I)-positive cells. Results are shown from $n=5$ independent experiments. (B) Synergistic induction of $\alpha$ GSU expression through BM P and Wnt signaling. (a,e) E9.5 Rathke's pouch explants cultured in the presence of COS cells showed induction of only ACTH expression (a) as reveal ed by immunohistochemistry; no $\alpha$ GSU expression (e) is detectable. (b,c,f,g) Similar results were obtained as in a and e when E9.5 Rathke's pouch explants were cultured with COS cells secreting either BM P4 or Wnt5a al one. (d,h) Coculturing of COS cells producing both BMP4 and Wnt5a with E9.5 Rathke's pouch explants resulted in induction of $\alpha$ GSU expression (h). Results are from $n=4$ independent experiments. (C) Expression of a POTX-N oggin transgene leads to an arrest of pituitary development. (a) Wild-type (WT) littermate at E17.5 stained for ACTH. (b) Phenotypic appearance of the pituitary gland in a POTX-N oggin transgenic embryo at E17.5. The gland has not progressed beyond a single layer epithelium stage reminiscent of Rathke's pouch at E10.0. A connection towards the oral cavity still remains. (c) Higher magnification of b. Arrows mark the few ACTH-positive cells that can be found in this gland. (d,e) Immunohistochemical staining of adjacent sections with $\alpha$ GSU and Pit-1 antisera, respectively. No positive cells for either of the two markers could be found. Four independent transgene-positive embryos from this stage of gestation were obtained with three showing an abnormal phenotype. 
observed, even though Pit-1 expression was detected and growth-hormone-positive cells consistently appeared in these cultures. It is therefore likely that the coculture system does not fully maintain all of the three dimensional aspects of normal development, compelling in vivo experiments to evaluate signaling control of the entire process of pituitary organogenesis.

\section{BMP4 is required for pituitary organ commitment in vivo}

As gene deletions for BMP2 (Zhang and Bradley 1996) and BMP4 (Winnier et al. 1995) result in embryonic lethal phenotypes prior to any potential role in pituitary development, we took advantage of the fact that N oggin is reported to specifically and efficiently block the action of BMP2/BMP4 and only inefficiently BMP7, but not other known members of the TGF $\beta$ family (Zimmerman et al. 1996; Liem et al 1997), to investigate whether BMP signaling was required for initial pituitary organ commitment. In order to utilize such an in vivo approach, it was necessary to identify the regulatory sequences of an appropriate transcription unit that would sel ectivel y target a noggin transcription unit in an appropriate temporal and spatial fashion to Rathke's pouch. We found that $8 \mathrm{~kb}$ of $5^{\prime}$ cis-regulatory information of the P-OTX/Ptx1 gene (Lamonerie et al. 1996; Szeto et al. 1996; Lanctot et al. 1997) was capable of specifically di recting transgenic expression to the oral ectoderm and to Rathke's pouch in transgenic animals (D.P. Szeto and M.G. Rosenfeld, unpubl.). This transcri pti on unit permitted us to target misexpression of noggin in transgenic animals (Fig. 2C). In the noggin transgenic embryos the development of Rathke's pouch was arrested, exhibiting a morphological appearance resembling an E10 Rathke's pouch, even at E17.5 (Fig. 2C). Immunohistochemical staining for celltype-specific markers reveal ed that neither $\alpha \mathrm{GSU}$ - nor Pit-1-positive cells could be identified, with only a few ACTH-positive cells detectable. This phenotype very closely resembles that reported for the LIM homeodomain factor Lhx3/P-Lim gene-deleted mouse (Sheng et al. 1996), which is induced in the Shh nonexpressing ectoderm after contact with the neuroepithelium, and which has been interpreted to reflect a failure of initial organ commitment and proliferation events. Based on our current understanding of noggin function and the fact that BMP4, but not BMP2 or BMP7, could be detected in the neuroepithelium at this time, our data strongly suggest that BM P4 activity is itself required for initial organ commitment and development of the pituitary anlage.

\section{BMP2 signal requirement for the Pit-1 lineage}

The appearance of BMP2 on E10.5 at the ventral limit of the presumptive Rathke's pouch at the Shh boundary next raised the issue of the role of BMP2, and suggested that its expression in the developing gland might be a critical component of the loss of dependence on the ventral diencephalon signaling after E10.5. To gain func- tional insight into the potential role of the endogenous BMP2 activity in subsequent cell-type determination, we took advantage of the fact that BM P signaling is mediated through a BM P receptor (BM PR) system of type I and type II receptors, which both have low affinity for their ligand and only together achieve high affinity binding (for review, see M assagué 1996) and therefore is susceptible to a dominant-negative approach. Although 4.6 $\mathrm{kb}$ of $5^{\prime}$ cis-regulatory information of the $\alpha \mathrm{GSU}$ gene, expressed early in Rathke's pouch development (Simmons et al . 1990; Kendall et al. 1994), have been reported to target to all the cells of Rathke's pouch (Kendall et al. 1994), we used $14 \mathrm{~kb}$ of 5' cis-regulatory information of the $\alpha$ GSU gene to more efficiently misexpress a dominant-negative BM PR1A receptor (Suzuki et al. 1994) in transgenic animals prior to cell type determination. We chose this BMPR isoform because it was previously shown that this receptor specifically binds to BM P2 and BM P4, but not activins (for review, see M assague 1996). Mice expressing the transgene exhibited a dwarf phenotype. Analysis of the pituitary gland showed a highly hypoplastic phenotype, effecting primarily the anterior lobe (Fig. 3). In situ hybridization revealed that the Pit-1 lineage was al most completely absent (Fig. 3e,f,g,l ,m,n); with only rare positive cell clones, similar to the few remaining clusters of Pit-1 lineage cells described in the Prop-1-defective, Ames (df) mouse (Gage et al. 1996; Sornson et al. 1996). In contrast, the remaining cells in the anterior lobe expressed either POMC (Fig. 3b,i) or $\alpha \mathrm{GSU}$ (Fig. 3c,j) and the dominant-negative BM PR transgene, as shown by hybridization with a transgene-specific probe (human GH) [hGH Fig. 3a,h], with a substantial percentage of $\alpha \overline{\mathrm{GSU}}$-positive cells also positive for the gonadotrope-specific markers $\mathrm{LH} \beta$ and $\mathrm{FSH} \beta$ (Fig. $3 d, \mathrm{k}$; data not shown). Because the dominant-negative receptor can function only in a cell-autonomous fashion, this result further implies that the precursors of the Pit-1 lineage are initially temporally specified as $\alpha \mathrm{GSU}$-positive cells, as terminally differentiated GH- and prolactinpositive cells do not express $\alpha \mathrm{GSU}$, consistent with a broad, early pattern of $\alpha \mathrm{GSU}$ expression (Simmons et al. 1990; Kendall et al. 1994). Whereas the $\alpha$ GSU population was clearly diminished, determination of the gonadotrope lineage was consistently observed, as might be expected because the dominant-negative receptor would be least effective in inhibiting highest levels of BMP activity most ventrally, where the gonadotrope lineage originates.

\section{Wnt4 is involved in pituitary cell-type expansion}

Of the known Wnt family members we could detect only low levels of Wnt4 transcripts during pituitary development. As shown in Figure 4, analysis of Wnt4 $4^{-1-}$ mice (Stark et al. 1994) at E17.5 revealed a clear reduction in cell number in the anterior pituitary gland of Wnt4 mutant animals compared to their wild-type littermates. Immunohistochemical analysis exhibited a drastic reduction in number of the ventral $\alpha \mathrm{GSU}, \mathrm{TSH} \beta$, and $\mathrm{GH}$ cell populations, without alteration in dorsal ACTH-ex- 
Treier et al.

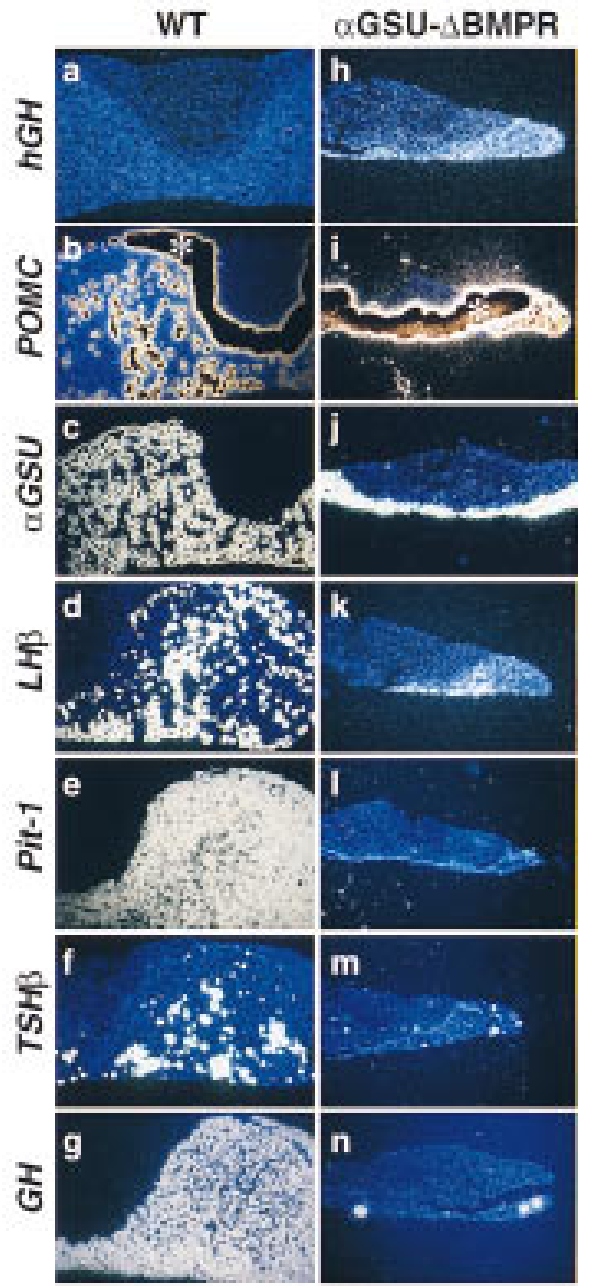

Figure 3. Role of endogenous BMP activity in cell-type determination. Pituitary phenotype of mice expressing the $\alpha \mathrm{GSU}$ $\triangle$ BMPR transgene. Pituitaries of a 8-week-old $\alpha \mathrm{GSU}-\Delta \mathrm{BM} P R$ transgenic mouse $(h-n)$ and its wild-type littermate $(a-g)$ are shown. In situ analysis for Pit-1 (e,l) and the trophic hormones POMC (b,i), $\alpha \mathrm{GSU}(\mathrm{c}, \mathrm{j}), \mathrm{LH}(\mathrm{d}, \mathrm{k}), \mathrm{TSH} \beta(\mathrm{f}, \mathrm{m})$ and GH $(\mathrm{g}, \mathrm{n})$, as well as a transgene specific probe hGH $(a, h)$ are shown. The asterisk $\left(^{*}\right)$ in $b$ marks the intermediate lobe that expresses POMC at such a high level that the region is overexposed and hence black. Three independent founders exhi bited a dwarf phenotype.

pressing corticotropes. Therefore, we propose that Wnt4 al one, or together with yet unkown members of the Wnt family, represents an intrinsic signaling molecule required for at least the expansion of some pituitary-celltype precursors, anal ogous to the role proposed for other Wnt family members in various developmental systems, such as the requirement for Wnt signaling in expansion of neural crest and CNS progenitors (Ikeya et al. 1997).

Attenuation of the BMP2 signal is required for terminal differentiation

Terminal differentiation of Pit-1 cell types occurs only by E15.5-16.5 (Simmons et al. 1990; Japon et al. 1994), by which time BMP2 expression is no longer detected. We therefore wished to investigate whether the suppression of BM P2 activity was required for terminal differentiation of pituitary cell phenotypes. To address this question, BMP2/4 was misexpressed under the $\alpha$ GSU cisregulatory elements in transgenic mice; immunohistochemical analysis on E17.0, well after the appearance of terminal differentiation markers, revealed that $\alpha \mathrm{GSU}$, $\mathrm{TSH} \beta$, growth hormone, and prolactin were not present (Fig. 5b-e, I-o), whereas A CTH was unaffected (Fig. 5a,k). These data suggest that the physiological attenuation of BMP2 expression is a critical component of terminal differentiation, as sustained expression of BM P activity results in a block of terminal differentiation of these four cell types. As the gland was not hypoplastic, and even hypercellular, we asked whether lineage determination had occurred. M arker gene expression was assessed by in situ hybridization. Transcripts for Pit-1, Isl-1, and GATA-2 were present, showing that lineage determination had indeed occurred (Fig. 5g-i, q-s). Expression of GATA-2 and IsI-1 has been noted in permanent gonadotrope and thyrotrope cell lines (Steger et al . 1994), and we

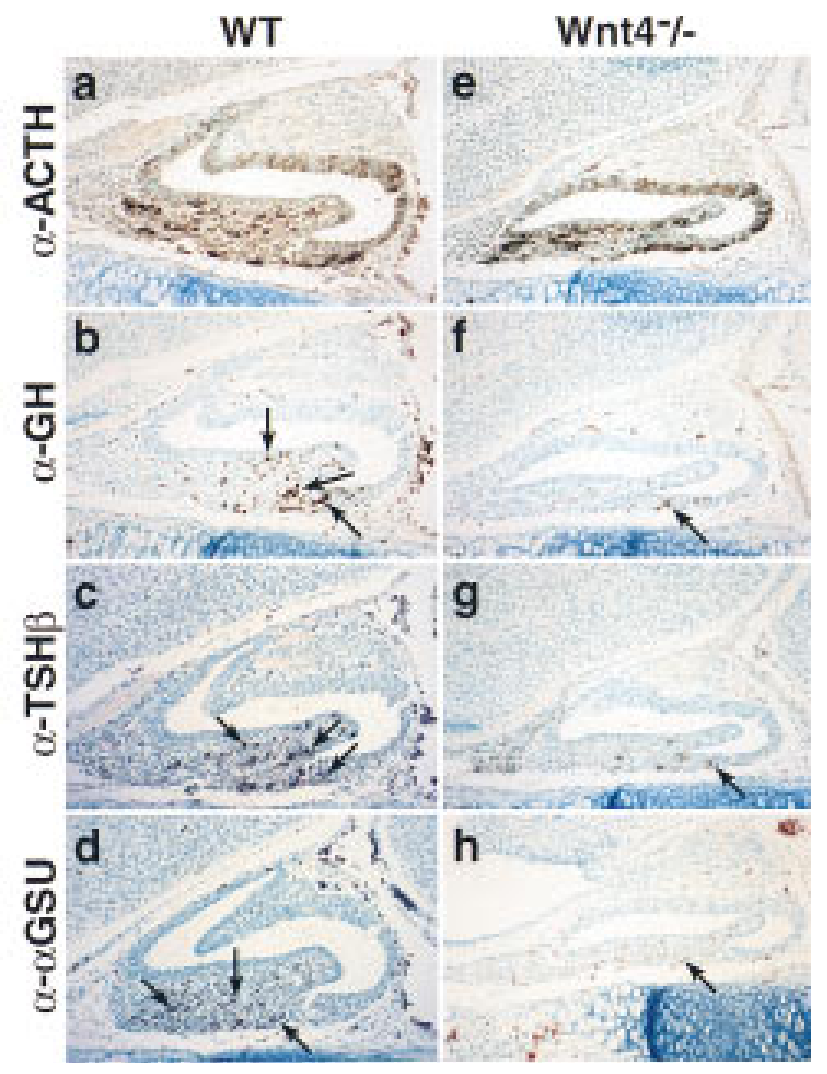

Figure 4. Wnt4 affects cell type expansion in the pituitary gland. Pituitary phenotype in Wnt $4^{-1-}$ mutant animals at E17.5 (e-h) compared to wild-type littermate $(a-d)$. Immunohistochemical analysis for the trophic hormones ACTH (a,e), GH $(b, f), \operatorname{TSH} \beta(c, g)$, and $\alpha \mathrm{GSU}(\mathrm{d}, \mathrm{h})$ are shown. Arrows indicate positive cells for the corresponding hormones in the mutant and wild-type pituitaries. Only a few positive cells for $\mathrm{GH}, \mathrm{TSH} \beta$, and $\alpha \mathrm{GSU}$ are present in the pituitaries of $\mathrm{Wnt}^{-1-}$ mutant animals. Five pairs of embryos were analyzed. 
Signaling gradients in pituitary organogenesis
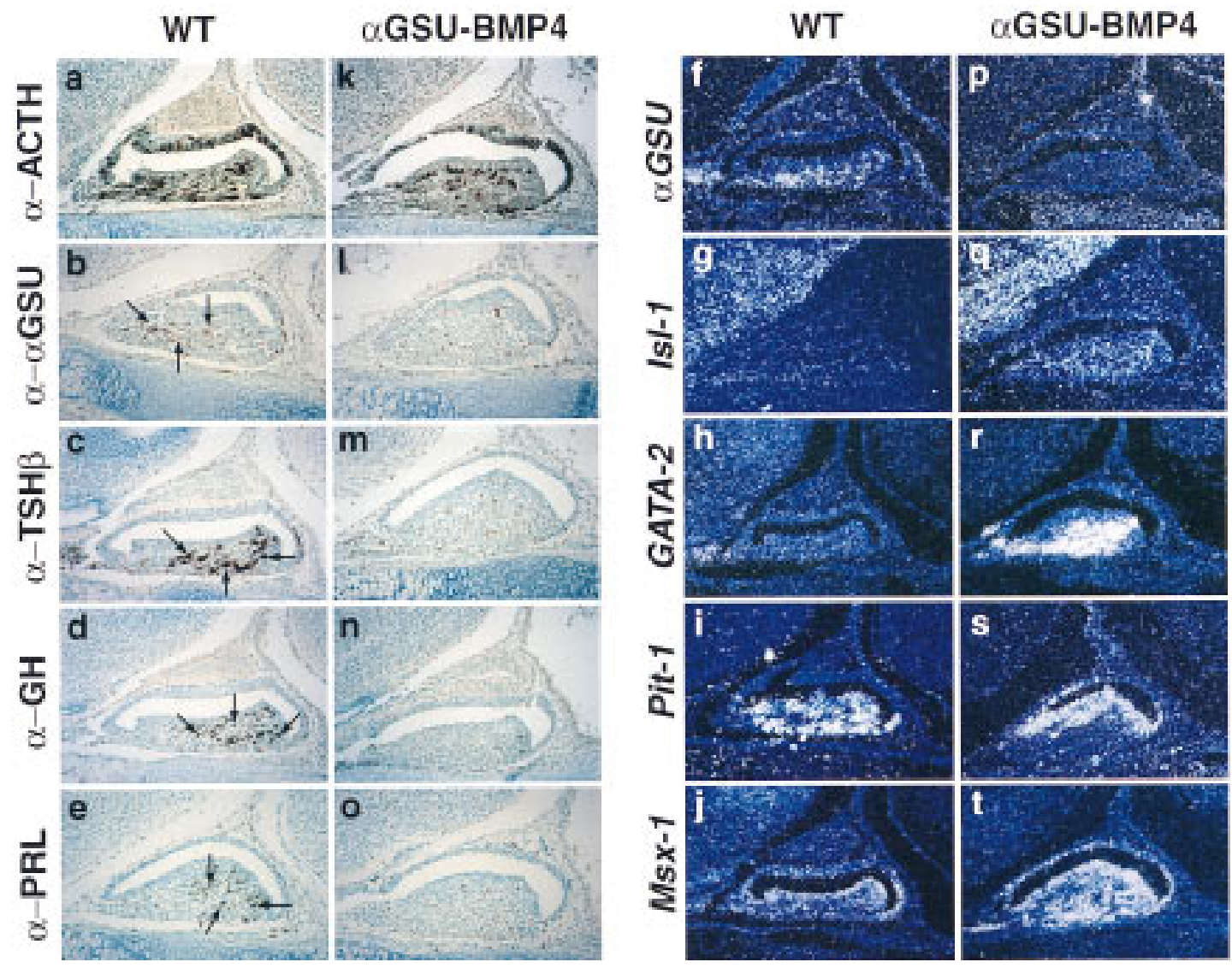

Figure 5. Prolonged BMP activity inhibits terminal differentiation. Phenotypic appearance of the pituitary gland in $\alpha \mathrm{GSU}-\mathrm{BM} \mathrm{P4}$ transgenic embryos at E17.0. Pituitaries of an E17 transgenic embryo (k-t) and its wild-type littermate (a-j) are shown. Immunohistochemical analysis for the trophic hormones ACTH (a,k), $\alpha \mathrm{GSU}(\mathrm{b}, \mathrm{l}), \mathrm{TSH} \beta(\mathrm{c}, \mathrm{m}), \mathrm{GH}(\mathrm{d}, \mathrm{n})$, and PRL (e,o) are shown. Arrows indicate positive cells for the corresponding hormones in the wild-type mouse. In situ analysis was performed with the following markers: $\alpha$ GSU (f,p), Isl-1 (g,q), GATA-2 (h,r), Pit-1 (i,s), and Msx-1 $(\mathrm{j}, \mathrm{t})$. Four independent transgenic embryos from this stage of gestation were analyzed, all showing an abnormal phenotype.

found that GATA-2 shows a ventrally restricted expression pattern, similar to that of Isl-1 (J.S. Dasen, S.M. O'Connell, and M.G. Rosenfeld, unpubl.). Interestingly, the GATA-2/Isl-1-positive cell population is strongly expanded, with GATA-2, but not IsI-1, being highly transcriptionally induced. Thus the ventral cell types appear to respond directly to the BMP signal pathway by upregulation of GATA-2. At the same time Msx-1, one of the relatively few established target genes of the BM P2/ 4 pathway (Vai nio et al . 1993), exhibited a marked up regulation throughout the gland, whereas in a wild-type gland Msx-1 was detectable at E17.0 only in the perilumenal cells (Fig. 5j,t). Because it has been shown that Msx-1 can function as a transcriptional repressor in other systems, such as in muscle differentiation (Woloshin et al. 1995) it is tempting to speculate that sustained expression of Msx-1 may, at least in part, account for the observed phenotype.

\section{FGF8 prevents ventral-cell-type determination}

The recent observation that signaling through the receptor tyrosine kinase/M AP kinase (Erk1/2) pathway leads to the dominant inhibition of BM P activity (Kretschmar et al. 1997) is highly suggestive of the possibility that FGF8 expressed in the ventral diencephalon/infundibulum counteracts the ventral BM P signal. To test a model proposing that FGF8 and BM P2 represent counteracting activity gradients in the developing gland, we misexpressed FGF8 under the $\alpha$ GSU cis-regulatory el ements in early Rathke's pouch. The pituitary gland of such transgenic animals exhibited a dramatic phenotype, with severe dysmorphogenesis and enlargement. Immunohistochemical analysis for the trophic hormones $\mathrm{MSH}$, ACTH, GH, TSH $\beta, \alpha \mathrm{GSU}$, and LH $\beta$ (Fig. 6; data not shown) revealed that in the more severe phenotypes (Fig. $6 f-j)$, cell lineages including gonadotropes, thyrotropes, somatotropes, and lactotropes were missing (Fig. 6h-j), whereas there was a greatly expanded population of MSH- and ACTH-expressing cells detected (Fig. 6f,g). Furthermore, expression of Pit-1, Isl-1, and GATA-2 was not detected (data not shown), indicating that determination of the Pit-1 and gonadotrope lineage had failed to occur. These data are consistent with the idea that FGF8 is critical for determination of the dorsal cell phenotypes, which have proved to be corticotropes (producing 
Figure 6. FGF8 promotes proliferation and opposes BMP activity in the pituitary gland. Phenotypic appearance of the pituitary gland in $\alpha$ GSU-FGF8 transgenic embryos at E17.5. Two transgenic embryos are shown, because the phenotype became more severe with higher copy number of the transgene $[\alpha G S U-F G F 8$ (f-j) strong phenotype, $\alpha$ GSU-FGF8 (k-0) weaker phenotype]. In both cases the gland exhibited striking dysmorphogenesis and increased cellularity (all photomicrographs taken at the same magnification). In $\alpha$ GSU-FGF8 $(f, g)$, new clusters of lumenal-like cells have budded off (open arrows). Immunohistochemical analysis for the trophic hormones MSH $(a, f, k)$, ACTH $(b, g, l), G H$ (c,h,m), TSH $\beta(d, i, n)$, and $\alpha$ GSU $(e, j, o)$ are shown, with selective loss of GH (h), TSH $\beta$ (i), and $\alpha$ GSU (j) in the case of the more severe phenotype and TSH $\beta$ (n) and $\alpha$ GSU (o) in the case of the weaker phenotype. The arrows mark clusters of positive cells for the respective hormones analyzed. $\mathrm{N}$ ote that the dark dots, especially seen in the $\alpha-\alpha$ GSU analysis of the $\alpha$ GSU-FGF8 (o) transgene, represent blood cells and not positive staining. Seven independent transgenic embryos at this stage were analyzed, with three showing the more severe abnormal phenotype then the other four.

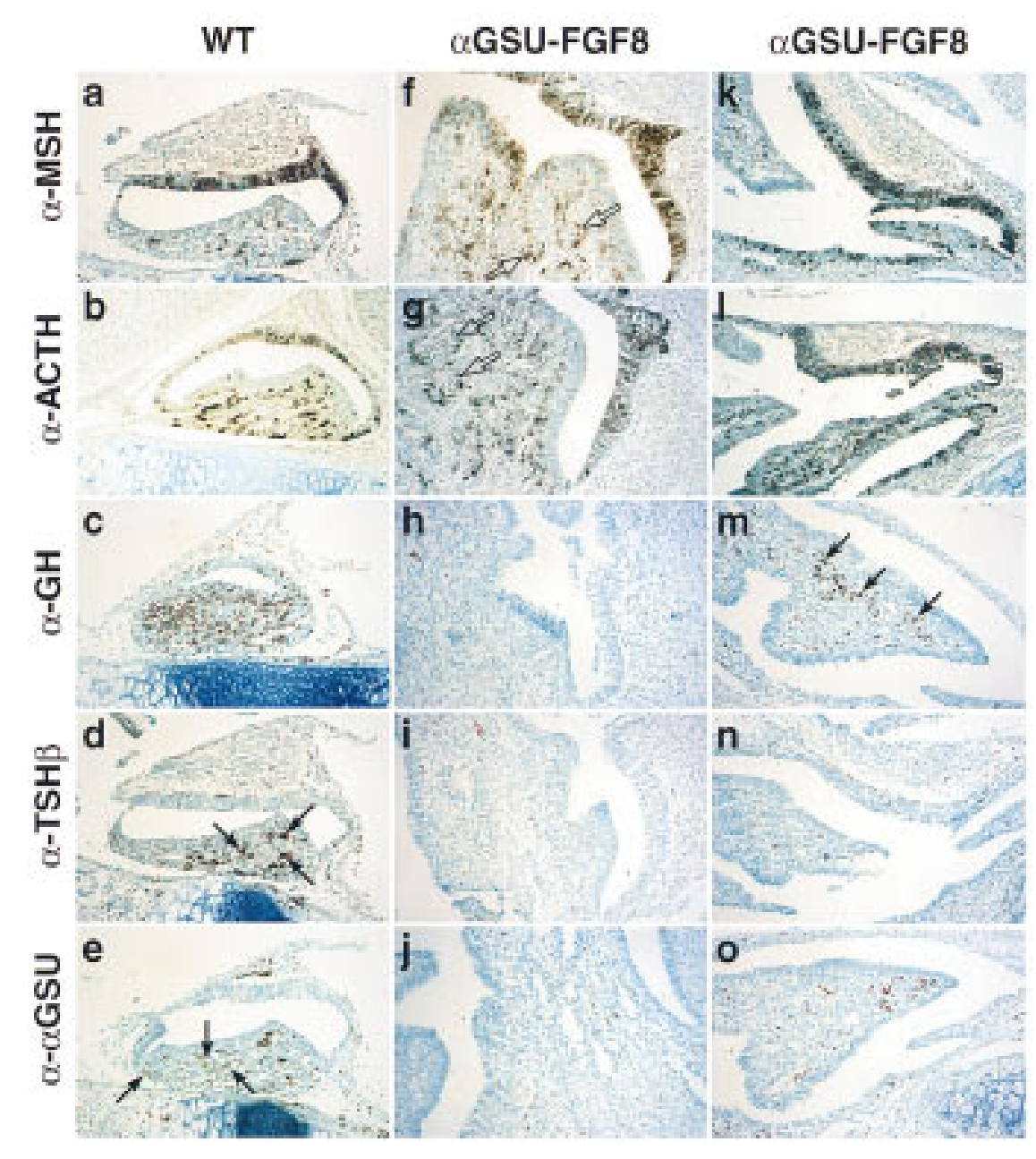

ACTH) and melanotropes (producing MSH), with higher levels of FGF8 activity actually suppressing all ventral cell types.

According to a gradient model, gonadotropes and thyrotropes should be most sensitive to FGF8 signaling as they are determined in the region most ventral to the source of FGF8 expression. Consistent with this model, transgenic embryos with a lower copy number of the FGF8 transgene exhibited a less severe phenotype (Fig. $6 k-0)$, with the appearance of some growth hormone positive somatotropes (Fig. $6 \mathrm{~m}$ ), which arise dorsally to the thyrotrope or gonadotrope cell populations, yet still excluding thyrotropes and gonadotropes entirely (Fig. $6 n, 0)$. These data therefore suggest counteracting BM P2/ FGF8 activity gradients in determination of specific pituitary cell phenotypes.

Dorsoventral gradients of transcription factor expression in the developing pituitary gland

Based on these data we predicted that one should be able to find transcription factors with spatially and temporally restricted expression patterns that would reflect these two opposing activity gradients. In contrast to factors such as P-OTX/Ptx1 that exhibit uniform expres- sion (Fig. 7B), Brn-4 (Mathis et al. 1992), a POU homeodomain transcription factor, appears ventrally at E10-10.5 and ultimately becomes expressed throughout the ventral half of the maturing nascent gland (Fig. 7B). We isolated several new genes exhibiting restricted expression patterns in Rathke's pouch using RT-PCR. One is a novel member of the Winged-helix (Forkhead) transcription factor family, that we refer to as P-Frk (for pituitary forkhead factor; Fig. 7A). As shown in Figure 7B, expression of P-Frk was initiated at the most ventral part of Rathke's pouch, coincident with the appearance of the ventral Shh/BM P2 boundary and remained restricted at later times to the most ventrorostral part of the gland, further subdividing the Brn-4 expression domain. In contrast to P-Frk, the LIM-homeodomain factor Isl-1 (Thor et al. 1991) appeared to be more widely expressed initially and subsequently became ventrally restricted, exhibiting a temporally and spatially overlapping expression with P-Frk during pituitary organogenesis. Six-3 (Oliver et al. 1995) and Prop-1 (Sornson et al. 1996) are initially expressed in a complementary dorsoventral gradi ent, extending to partial ly overlap the Brn-4 expression domain (Fig. 7B; data not shown).

On the most dorsal aspect of the developing gland, directly opposite to the highest levels of FGF8 expres- 
A

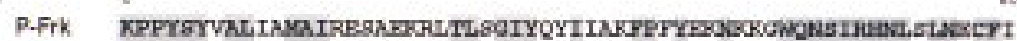

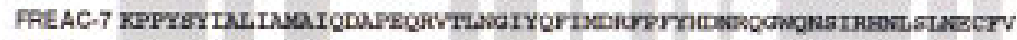

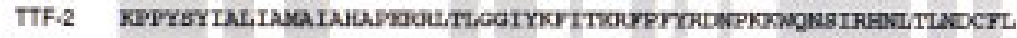

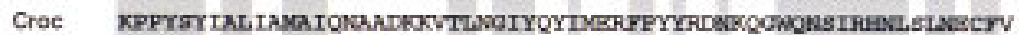

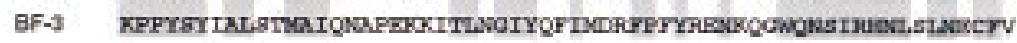

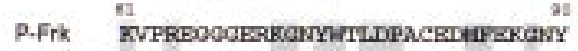

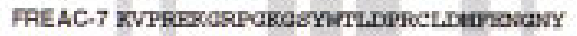

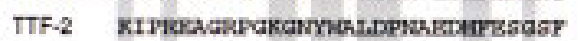

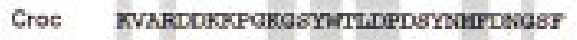

BF-3 RVPRDCKRFGKG

B
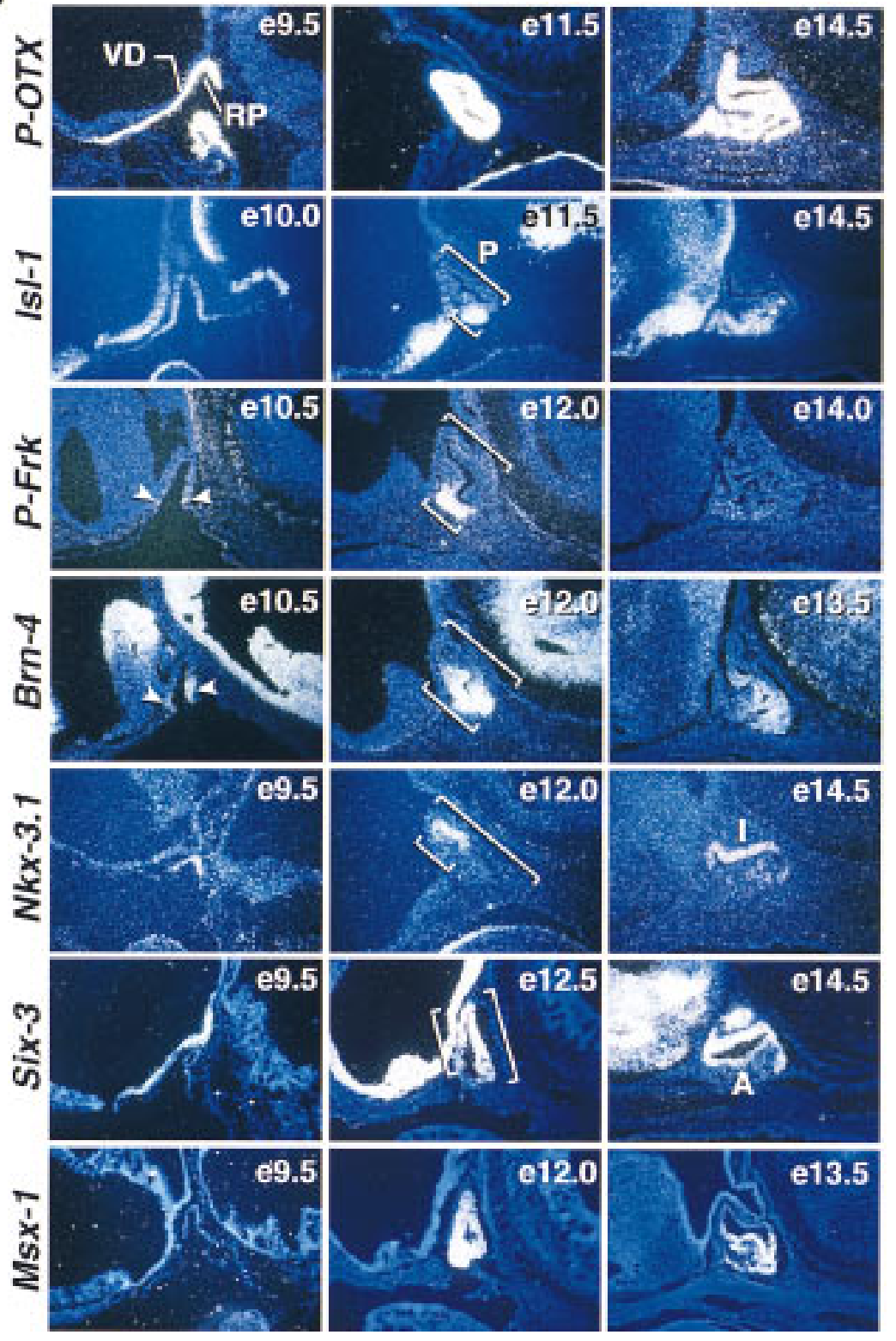

Figure 7. Patterning of Rathke's pouch by spatially restricted expression of transcription factors. (A) Comparison of the amino acid sequence of the new Winged-helix transcription factor P-Frk to that of other related Wingedhelix (Forkhead) factors. (B) In situ hybridization analysis for P-OTX, Isl-1, P-Frk, Brn-4, Nkx-3.1, Six-3, and Msx-1 during early stages of pituitary devel opment. N otice that P-Frk expression was detected at E10.5 in the most ventral part of Rathke's pouch (arrowheads). Brackets mark the position of the pituitary and the different dorsal-to-ventral expression of each transcription factor, respectively. (e) Embryonic day of mouse development; (A) anterior lobe; (I) intermediate lobe; (RP) Rathke's pouch; (P) pituitary; (VD) ventral diencephaIon. sion, a N kx-related homeobox gene, Nkx-3.1 (Bieberich et al . 1996), was found to be the most dorsally restricted known transcription factor expressed in Rathke's pouch and further subdivides the Prop-1/Six-3-positive field.
The expression of genes encoding these distinct classes of transcription factors in overlapping dorsoventral quadrants indicates a division of the nascent Rathke's pouch into regions with distinct complements of transcription 
factors, suggesting that cell lineage determination may well have already occurred by this stage of pituitary organogenesis, consequent to the proposed BMP2/FGF8 gradients.

\section{Discussion}

We have obtained evidence for three phases of signaling control in generating the hormone-producing pituitary cell types, providing a model for the generation of specific cell phenotypes from a common primordium in mammalian organogenesis. Our data support a model of pituitary development (Fig. 8) in which dorsal neuroepithelial signals, particularly BM P4, are critical for initial pituitary organ commitment. The subsequent establishment of a ventral boundary at Shh-expressing and -nonexpressing ectodermal domains within the oral ectoderm appears to function as an organizing center, resulting in induction of BMP2 in Rathke's pouch. Later, the action of FGF8 dorsally and of BMP2 ventral ly, may dictate the observed restricted dorsal or ventral expression patterns of specific transcription factors in the nascent Rathke's pouch that are proposed to determine specific pituitary cell lineages. Thus, the pituitary gland provides a case in which related BMP factors serve sequential roles, first dorsally and then ventrally, to successively determine organ and distinct cell types within the pituitary gland. Finally, attenuation of specific signals is required for terminal differentiation of distinct cell phenotypes. These data lead to the conclusion that each of the mature cell types are determined relatively early during organogenesis, at the Rathke's pouch stage, in a strict ventral-todorsal fashion, with gonadotropes, thyrotropes, somatotropes/lactotropes, corticotropes, and mel anotropes rep-

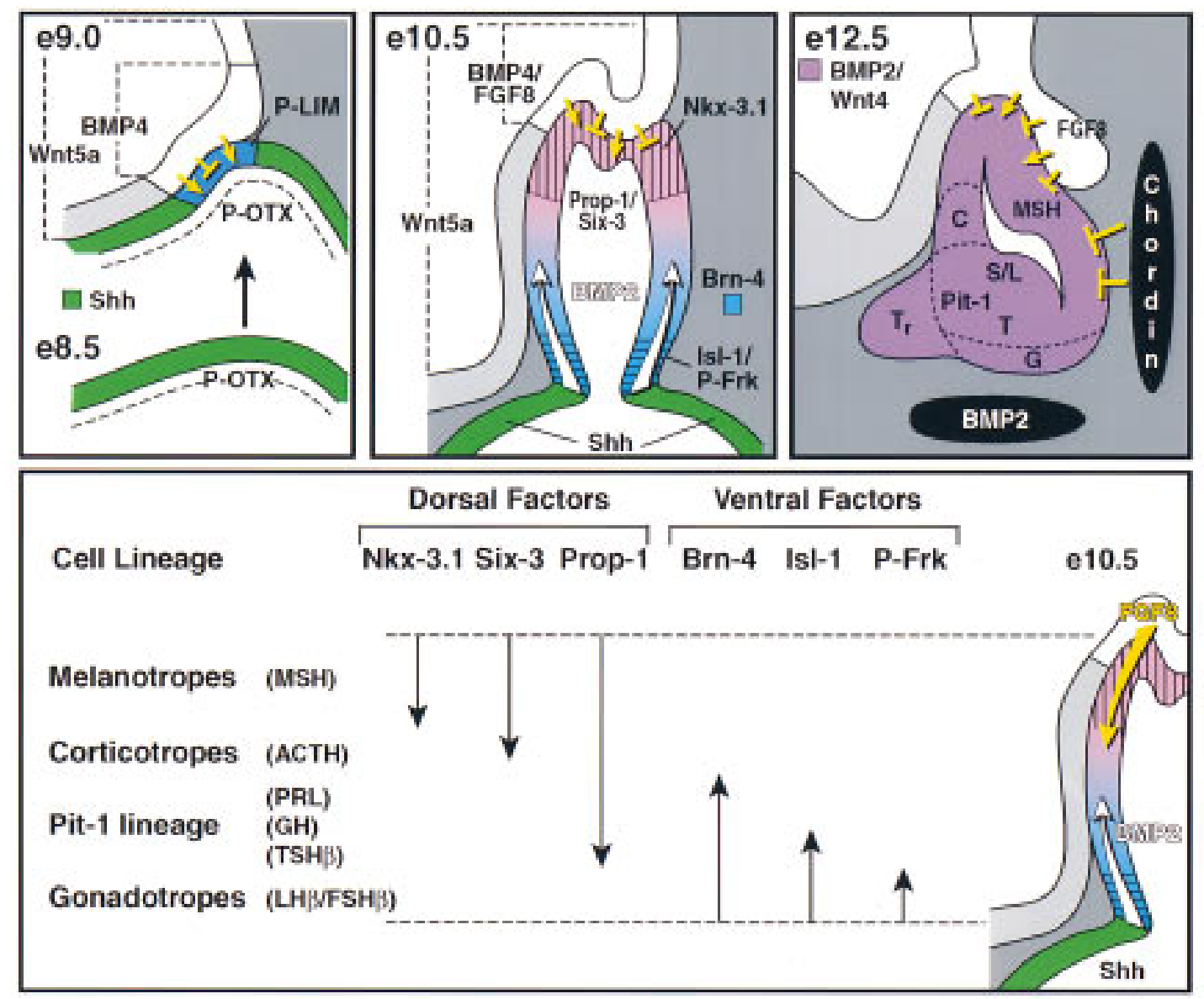

Figure 8. Model of cell lineage determination in pituitary ontogeny. At E8.5 (e8.5) in mouse development, Shh and P-OTX are continuously expressed throughout the oral ectoderm. Signals from the ventral diencephal on, most prominently BM P4, suppress the expression of Shh, creating a Shh-nonexpressing zone, the primordium of the nascent Rathke's pouch and at the same time induce P-Lim/Lhx3. The boundary between the oral ectoderm expressing Shh and the nonexpressing Rathke's pouch function as an organizing center for ventral gene induction, including BMP2. At E10.5 Rathke's pouch has formed and the infundibulum is visible. FGF8, expressed in the infundibulum, functions antagonistically to BMP2, resulting in ventrodorsal BMP and dorsoventral FGF activity gradients in Rathke's pouch. This leads to the induction of several temporally and spatially restricted transcription factors, postulated to combinatorially divide Rathke's pouch into zones with different identities. These zones are proposed to impose the determination of cell lineages at this devel opmental stage. During the next 2 days of cell lineage expansion, the BM P2 activity gradient in Rathke's pouch is reinforced by ventral expression of BM P2 in the underlying condensing mesenchyme and counteracted by dorsal expression of FGF8 and caudal expression of chordin. 
resenting the progressively more dorsally determined cell types (Fig. 8).

Initial phase of pituitary development: dorsal neuroepithelial signals in pituitary organ commitment

The mammalian pituitary gland represents an example in which initiation of organ development depends on contact between two distinct ectodermal cell layers, whereby the ventral diencephal on produces the inducing factor(s) and the oral ectoderm provides the competence required to respond to this signal (s) (Kimura et al . 1996), similar to established classical embryological experiments (Spemann 1938). BM P4, FGF8, and Wnt5a represent the only known members of these three families of regulatory molecules that are expressed in the region of the ventral diencephal on that directly contacts the invaginating oral ectoderm destined to become the pituitary gland. These factors appear to be expressed in overlapping, but distinct fashion, with BM P4 exhibiting the most restricted expression, in contrast to the more extended expression of Wnt5a in the ventral di encephal on.

The ability to appropriately target noggin misexpression by the use of specific regulatory sequences of the P-OTX/Ptx-1 gene has permitted the initial proof in vivo of a required role for $\mathrm{BM} P$ activity in pituitary organ commitment. N oggin can interact with BM P4 and BM P2 and to lesser extent with BMP7 (Zimmerman et al. 1996), but neither BM P2 or BM P7 appear to be expressed in the ventral diencephal on, suggesting that BM P4 is the signaling molecule required for initial determination of the pituitary gland. As the initial invagination of oral ectoderm is not lost in the noggin transgenic mice, the phenotype of these mice is virtually identical to that of the Lhx3/P-Lim( $-1-$ mice (Sheng et al. 1996). In both cases, only a few ACTH-positive cells are present among the ectodermal cells. Therefore, it is likely that BM P4 is either directly or indirectly responsible for Lhx3/P-Lim induction or represents a parallel requirement for the same step of organ commitment. Our experiments further show that FGF8 is a potent mitogen within Rathke's pouch, leading to hyperproliferation when ectopically expressed. Therefore, FGF8, as in other systems (C rossley et al. 1996; Lee et al. 1997; N eubuser et al. 1997), is required at least for the growth of Rathke's pouch. Together these studies have provided the initial in vivo proof that at least one of the signaling molecules expressed in the ventral diencephal on, BM P4, is required for pituitary organ commitment.

Second phase of pituitary development: counteracting dorsoventral FGF8/BMP2 gradients

The onset of pituitary organogenesis is al so marked by a striking restriction of Shh, uniformly expressed in oral ectoderm, from the invaginating Rathke's pouch, resulting in a molecular boundary in the oral ectoderm. The second phase of pituitary development appears to involve a ventral-to-dorsal gradient of BMP2 expression, beginning at the boundary of Shh expression. Based on the effects of the expression of a specific dominant-negative receptor, the role of BM P2 appears to be determination of all the ventral cell phenotypes, including specification of the Pit-1 lineage. We suggest that determination of the most ventral cell lineage specifying the gonadotropes is al so dependent on BM P2, although the dominant-negative receptor inefficiently blocked the higher ventral BM P2 activity. Indeed, overexpression of BMP2/4 expands this ventral lineage marked by increased expression of GATA-2. In contrast, melanotropes producing $\mathrm{MSH}$, and corticotropes producing ACTH were not affected, consistent with a model that they represent the dorsal cell types.

In addition to the ability of FGF8 to increase proliferation of the nascent pituitary gland, it al so exerts a central role in dorsal cell type determination. Overexpression of FGF8 markedly increases the melanotrope and corticotrope populations, and abolishes appearance of the ventral gonadotrope, thyrotrope, somatotrope, and lactotrope cell types. Consistent with the model of a dorsalto-ventral FGF gradient, at lower levels of FGF8 we now observed appearance of a somatotrope population. Therefore, FGF8 appears to exert several roles in proliferation and subsequently in cell type determination, similar to its role in limb development and patterning at the midbrain/hindbrain boundary (Crossley et al. 1996; Lee et al. 1997). In concert with previous anatomical evidence (Japon et al. 1994; Simmons et al. 1990), we suggest that early in Rathke's pouch development, the six hormoneproducing cell types are determined in a ventral-to-dorsal gradient, generating gonadotropes, thyrotropes, somatotropes, lactotropes, corticotropes, and melanotropes, respectively.

We have identified a series of transcription factors that are expressed in overlapping dorsal-to-ventral or ventral to dorsal gradients, consistent with overlapping patterns of factors that could combinatorally determine specific cell types. Among the factors identified is a member of the N kx family, N kx-3.1 (Bieberich et al. 1996), which is the most dorsally expressed transcription factor thus far identified. Expression of several genes encoding transcription factors, including Six-3, extend more ventrally. Conversely, a series of ventrally expressed factors exhibit progressively more dorsal extension in thei $r$ field of expression. A novel forkhead factor, P-Frk, has proved to be the most ventrally expressed factor, whereas GATA2, Isl-1, and Brn-4 exhibit progressively more dorsal expression, overlapping with Six-3 and Prop-1 (Fig. 8). It is noteworthy that the closest related forkhead member to P-Frk, TTF-2 is also expressed in the pituitary gland and is involved in thyroid gland cell-type determination (Zannini et al. 1997). Consistent with the hypothesis that expression of these factors are generated by gradients of signaling molecules, we have found that perturbation of the BM P2/FGF8 gradients in vivo al ters boundaries of expression of these factors. For example, overexpression of BM P2/4 extended the boundaries of IsI-1 and GATA-2 expression dorsally, linking the patterns of induced transcription factors to generation of specific cell types. 
Therefore, the sequential roles of BM P4 expressed in the ventral di encephal on and BM P2 expressed within the pituitary gland are conceptually analogous to the proposed cascade of TGF $\beta$ inductive signals leading to neuronal patterning in the dorsal spinal cord (Liem et al. 1997) and the demonstration that Dpp can serve as a Iong-range signal (N ellen et al . 1996), exhibiting concentration-dependent effects on cell type specification (Lecuit et al. 1996).

The initial appearance of BM P2 immediately adjacent to the Shh boundary raises intriguing questions concerning the role, if any, of Shh in pituitary development. Targeting Shh under the $\alpha$ GSU 5'-flanking sequence resulted in an enlargement of the embryonic rostral tip and an expansion of $\alpha \mathrm{GSU}$-positive, Isl-1-positive cell types, (M. Treier, A. Gleiberman, and M.G. Rosenfeld, unpubl.), suggesting that Shh here serves to expand ventral gonadotrope populations, consistent with the role of Shh in expansion of specific cell types in other organs (BelI usci et al. 1997). In addition to the role of BM P2, at least one Wnt (Wnt4), expressed within the developing gland as well as throughout the oral ectoderm appears to exert roles during pituitary devel opment. The pituitary glands of $\mathrm{Wnt}^{-1-}$ mice were hypocellular, but all cell types were correctly determined, suggesting that Wnt factors may exert roles in progenitor cell expansion in the pituitary gland similar to their roles in neural crest and CNS development (Ikeya et al. 1997). Thus members of the BMP, FGF, and Wnt families and possibly Shh, all participate in the progression from organ commitment to cell-type determination that occurs between E10 and E12, with the dorsal FGF and ventral BMP2 gradients being critical determinants of the hormone-producing pituitary cell types.

Third phase of pituitary development: cell-type differentiation requires attenuation of BMP signaling

We have provided evidence that attenuation of specific signaling molecules is itself a critical component of the terminal differentiation events in the pituitary gland, because continued expression of BMP2/4 results in a failure of terminal differentiation of all ventral cell types including gonadotropes, thyrotropes, somatotropes, and lactotropes, but not their determination, as marked by expression of IsI-1, GATA-2, and Pit-1. The importance of attenuation of BMP2 expression for progression to definitive cell types, indicates that negative control of BMP2 expression itself, is required to permit terminal differentiation. Because Msx-1 is a well described target gene for BMP2/4, it as well as other potential target genes may mediate the block of differentiation; similar to roles suggested for M sx-1 in muscle and tooth development (Vainio et al. 1993; Woloshin et al. 1995). It is interesting to note that overexpression of BMP2/4 in the pituitary gland does not result in inhibition of cell proliferation or the induction of apoptosis as reported in other systems (Bellusci et al. 1996).

The paradigm of pituitary development, characterized by serial determination events, thus extends our under- standing of the sequential roles of signaling gradients in the generation of specific cell phenotypes during mammalian organogenesis.

\section{Materials and methods}

Generation and identification of transgenic mice

Transgenic mice were produced as described (Crenshaw et al. 1989). Constructs were generated by inserting the respective cDN As between a rabbit $0.65-\mathrm{kb} \beta$-gl obin intron fragment at the 5 '-end and a $0.63-\mathrm{kb}$ poly(A) fragment of the human growth hormone gene at the $3^{\prime}$-end. Finally either a 14-kb fragment containing the mouse $\alpha \mathrm{GSU}$ promoter or a 8-kb fragment containing the mouse P-OTX promoter was inserted $5^{\prime}$ of this cassette, respectively. The P-OTX transgene was flanked on the $5^{\prime}$ and $3^{\prime}$ site with $2 \times$ the chicken $\beta$-gl obin insulator fragment (gift of G. Felsenfeld, NIH, Bethesda, MD). Mouse DNA was analyzed for integration of the transgene by PCR analysis using two specific primers for each transgene, respectively. The following CDN As were used, mouse $\triangle B M P R$ CDN A as described (Suzuki et al. 1994, gift of N. Ueto), the 5' out-of-frame ATGs were removed in the full-length mouse BM P4 CDN A (gift of B. Hogan, HHMI, Vanderbilt U niversity, N ashville, TN ) by mutagenesis, a EcoRI-HindlII DNA fragment encoding full-length Xenopus noggin (gift of R. Harland, University of California, Berkeley). The $\alpha$ GSU-FGF8 transgene contains the CDNA for FGF8b corresponding to isoform (1) in Crossley and Martin (1995) (gift of C.A. MacArthur, Washington University, St. Louis, MO).

The number of transgenics obtained at the reported stage and the number showing an abnormal phenotype (respectively in parentheses): POTX-N oggin, E17.5 (4;3); $\alpha$ GSU-DBMPR, 2 months (7;3); $\alpha$ GSU-BMP4, E17.5 (4;4); $\alpha$ GSU-FGF8, E17.5 $(7 ; 7)$. The generation of the Wnt4 $(-t-)$ mutant animals and genotyping are described in Stark et al. (1994).

In situ hybridization and immunohistochemistry

Isolation, fixation, and hybridization with ${ }^{35} \mathrm{~S}$-label ed antisense RN A probes and exposure were all done as previously described (Simmons et al. 1990). Immunohistochemistry was done on 57-mm thick paraffin sections stained by indirect immunoperoxidase method. Peroxidase activity was visual ized with DAB/ metal enhancer (Pierce, Rockford, II). Sections were counterstained with methyl green and mounted in Permount (Fisher). Antibodies are obtained and used diluted as follow: ACTH (Chemicon, Temecula, CA) 1:1000; GH, PRL, TSH $\beta$ (all from DAKO, Carpinteria, CA); $\alpha$ GSU (N ational Hormone and Pituitary Program) 1:1000; Pit-1 rabbit antiserum, 1:100. Anti-rabbit horseradish peroxidase-conjugated antibodies were from Chemicon and used in a 1:500 dilution.

\section{Isolation and cultivation of Rathke's pouch}

Mice used were $\left.F_{1}(C 57 B / 6) \times C B A\right)$. Embryos were obtained from dated pregnancies. The day of the vaginal plug was considered E0.5. Somite number was used in addition to determine developmental stages for early embryos. Rathke's pouch and ventral diencephal on were dissected from E9.5 and E10.5 mouse embryos after 10-20 min of treatment with collagenase (type I, Sigma) in DM EM (GIBCO) plus 10\% FCS, using el ectrolytically sharpened tungsten needles. Rathke's pouch and/or ventral diencephal on were placed on HAWP filters (Millipore), transferred on plastic floating rafts and cultivated in RPM I-1640 medium supplemented with $10 \%$ FCS for 6-8 days for filter induction experiments; or Rathke's pouch were cocultivated with 
COS cells that were transiently transfected with CMV-based expression vectors containing full-length BMP4 or Wnt5a cDNAs.

\section{Acknowledgments}

We are particularly grateful to $Y$. Furuta for communicating data prior to publication, Aimee K. Ryan and Anna Krones for their contributions, and Peggy $M$ yers for her expertise and generous assistance in preparation of illustrations, as well as the transgenic core facility at the Scripps Research Institute. For generously providing reagents and plasmids, we thank E. De Robertis, G. Felsenfeld, P. Gruss, R. Harland, B. Hogan, C.A. MacArthur, G. Martin, N. U eto, and S. Werner. We al so thank the $\mathrm{N}$ ational Hormone and Pituitary Program, $\mathrm{N}$ ational Institute of Diabetes, Digestive, and Kidney Diseases (NIDDK; Rockville, MD). M.T. was supported by a Boehringer Ingel heim Fonds postdoctoral fellowship; A.S.G. by a $\mathrm{N}$ ational Research Service Award from the National Institutes of Health $(\mathrm{NIH})$. M.G.R is an Investigator with the Howard Hughes Medical Institute. This work was supported by a grant from N IH (NIDDK).

The publication costs of this article were defrayed in part by payment of page charges. This article must therefore be hereby marked "advertisement" in accordance with 18 USC section 1734 solely to indicate this fact.

\section{Note}

The GenBank accession no. for the sequence described in this paper is AF060873.

\section{References}

Bach, I., S.J. Rhodes, R.V. Pearse, T. Heinzel, B. Gloss, K.M. Scully, P.E. Sawchenko, and M.G. Rosenfeld. 1995. P-Lim, a LIM homeodomain factor, is expressed during pituitary organ and cell commitment and synergizes with Pit-1. Proc. Natl. Acad. Sci. 92: 2720-2724.

Basler, K. and G. Struhl. 1994. Compartment boundaries and the control of Drosophila limb pattern by hedgehog protein. $\mathrm{Na}$ ture 368: 208-214.

Bellusci, S., R. Henderson, G. Winnier, T. Oikawa, and B.L. Hogan. 1996. Evidence from normal expression and targeted misexpression that bone morphogenetic protein (Bmp-4) plays a role in mouse embryonic lung morphogenesis. De velopment 122: 1693-1702.

Bellusci, S., Y. Furuta, M.G. Rush, R. Henderson, G. Winnier, and B.L Hogan. 1997. Involvement of Sonic hedgehog (Shh) in mouse embryonic lung growth and morphogenesis. De velopment 124: 53-63.

Bieberich, C., K. Fujita, W. He, and G. Jay. 1996. Prostate-spe cific and androgen-dependent expression of a novel homeobox gene. J. Biol. Chem. 271: 31779-31782.

Bumcrot, D.A. and A.P. M cMahon. 1995. Somite differentiation. Sonic signals somites. Curr. Biol. 6: 612-614.

Cadigan, K.M. and R. N usse. 1997. Wnt signaling: A common theme in animal development. Genes \& Dev. 11:32863305.

Couly, G. and N.M. LeDouarin. 1988. The fate map of the cephalic neural primordium at the presomitic to the 3-somite stage in the avian embryo. Development (Suppl.) 103: 101113.

Crenshaw, E.B.I., K. Kalla, D.M. Simmons, L.W. Swanson, and M.G. Rosenfeld. 1989. Cell-specific expression of the prolactin gene in transgenic mice is controlled by synergistic in- teractions between promoter and enhancer el ements. Genes \& Dev. 3: 959-972.

Crossley, P.H. and G.R. Martin. 1995. The mouse Fgf8 gene encodes a family of polypeptides and is expressed in regions that direct outgrowth and patterning in the developing embryo. Development 121: 439-451.

Crossley, P., G. Minowada, C. M acArthur, and G. M artin. 1996. Roles for FGF8 in the induction, initiation, and maintenance of chick limb development. Cell 84: 127-136.

Eagleson, G.W. and W.A. Harris. 1990. M apping of the presumptive brain regions in the neural plate of Xenopus laevis. J. Neurobiol. 21: 427-440.

Gage, P.J., M.L. Roller, T.L. Saunders, L.M. Scarlett, and S.A. Camper. 1996. Anterior pituitary cells defective in the cellautonomous factor, df, undergo cell lineage specification but not expansion. Development 122: 151-160.

Hermesz, E., S. Mackem, and K.A. Mahon. 1996. Rpx: A novel anterior-restricted homeobox gene progressively activated in the prechordal plate, anterior neural plate and Rathke's pouch of the mouse embryo. Development 122: 41-52.

Hogan, B. 1996. Bone morphogenetic proteins: Multifunctional regulators of vertebrate development. Genes \& Dev. 10: 1580-1594.

Ikeya, M., S.M . Lee, J.E. Johnson, A.P. M cM ahon, and S. Takada. 1997. Wnt signalling required for expansion of neural crest and CN S progenitors. Nature 389: 966-970.

Jacobson, A.G., D.M. Miyamoto, and S.-H Mai. 1979. Rathke's pouch morphogenesis in the chick embryo. J. Exp. Zool. 207: 351-366.

Japon, M.A., M. Rubinstein, and M .J. Low. 1994. In situ hybridization analysis of anterior pituitary hormone gene expression during fetal mouse development. J. Histochem. Cytochem. 42: 1117-1125.

Johnson, R.L. and C.J. Tabin. 1997. Molecular models for vertebrate limb devel opment. Cell 90: 979-990.

Jones, C.M., K.M. Lyons, and B.L.M. Hogan. 1991. Involvement of Bone Morphogenetic Protein-4 (BM P-4) and Vgr-1 in morphogenesis and neurogenesis in the mouse. Development 111: 531-542.

Kendall, S.K., D.F. Gordon, T.S. Birkmeier, D. Petrey, V.D. Sarapura, K.S. O'Shea, W.M. Wood, R.V. Lloyd, E.C. Ridgway, and S.A. Camper. 1994. Enhancer-mediated high level expression of mouse pituitary glycoprotein hormone $\alpha$-subunit transgene in thyrotropes, gonadotropes, and developing pituitary gland. Mol. Endocrinol. 8: 1420-1433.

Kimura, S., Y. Hara, T. Pineau, P. Fernandez-Sal guero, C.H. Fox, J.M. Ward, and F.J. Gonzalez. 1996. The T/ebp null mouse: Thyroid-specific enhancer-binding protein is essential for the organogenesis of the thyroid, lung, ventral forebrain, and pituitary. Genes \& Dev. 10: 60-69.

Kretschmar, M., J. Doody, and J. Massagué. 1997. Opposing BM $P$ and EGF signal ling pathways converge on the TGF-beta family mediator Smad1. Nature 389: 618-622.

Lamonerie, T., J.J. Tremblay, C. Lanctot, M. Therrien, Y. Gauthier, and J. Drouin. 1996. Ptx-1, a bicoid-rel ated homeo box transcription factor involved in transcription of the proopiomelanocortin gene. Genes \& Dev. 10: 1284-1295.

Lanctot, C., B. Lamolet, and J. Drouin. 1997. The bicoid-related homeoprotein Ptxl defines the most anterior domain of the embryo and differentiates posterior from anterior lateral mesoderm. Development 124: 2807-2817.

Lawrence, P. and G. Struhl. 1996. M orphogens, compartments, and pattern: Lessons from Drosophila? Cell 85: 951-961.

Lecuit, T., W.J. Brook, M. Ng, M. Calleja, H. Sun, and S.M. Cohen. 1996. Two distinct mechanisms for long range patterning by Decapentaplegic in the Drosophila wing. Nature 
381: 387-393.

Lee, S., P. Danielian, B. Fritzsch, and A.P. McMahon. 1997. Evidence that FGF8 signalling from the midbrain-hindbrain junction regulates growth and polarity in the developing midbrain. Development 124: 959-969.

Li, S., E.B. Crenshaw, E.J. Rawson, D.M. Simmons, L.W. Swanson, and M.G. Rosenfeld. 1990. D warf locus mutants lacking three pituitary cell types result from mutations in the POUdomain gene pit-1. Nature 347: 528-533.

Liem, K., G. Tremml, and T. Jessell. 1997. A role for the roof plate and its resident TGF-beta-related proteins in neuronal patterning in the dorsal spinal cord. Cell 91: 127-138.

Luo, X., Y. Ikeda, and K.L. Parker. 1994. A cell-specific nuclear receptor is essential for adrenal and gonadal development and sexual differentiation. Cell 77: 481-490.

Massagué, J. 1996. TGF $\beta$ signaling: Receptors, transducers, and Mad proteins. Cell 85: 947-950.

Mathis, J.M., D.M. Simmons, X. He, L.W. Swanson, and M.G. Rosenfeld. 1992. Brain 4: A novel mammalian POU domain transcription factor exhibiting restricted brain-specific expression. EMBO J. 11: 2551-2561.

Nellen, D., R. Burke, K. Basler, and G. Struhl. 1996. Direct and graded long-range signaling by Dpp. Cell 85: 357-368.

Neubuser, A., H. Peters, R. Balling, and G. Martin. 1997. Antagonistic interactions between FGF and BMP signaling pathways: A mechanism for positioning the sites of tooth formation. Cell 90: 247-255.

Oliver, G., A. Mailhos, R. Wehr, N.G. Copeland, N.A. Jenkins, and P. Gruss. 1995. Six3, a murine homologue of the sine oculis gene, demarcates the most anterior border of the developing neural plate and is expressed during eye development. Development 121: 4045-4055.

Piccolo, S., Y. Sasai, B. Lu, and E. De Robertis. 1996. Dorsoventral patterning in Xenopus: Inhibition of ventral signals by direct binding of chordin to BM P-4. Cell 86: 589-598.

Rusch, J. and M. Levine. 1996. Threshold responses to the dorsal regulatory gradient and the subdivision of primary tissue territories in the Drosophila embryo. Curr. Opin. Genet. Dev.6: 416-423.

Sheng, H.Z., A.B. Zhadanov, B. Mosinger Jr., T. Fujii, S. Bertuzzi, A. Grinberg, E.J. Lee, S.-P. Huang, K.A. M ahon, and H. Westphal. 1996. Specification of pituitary cell lineages by the LIM homeobox gene Lhx3. Science 272: 1004-1007.

Sheng, H.Z., K. M oriyama, T. Yamashita, H. Li, S.S. Potter, K.A. Mahon, and $\mathrm{H}$. Westphal. 1997. Multistep control of pituitary organogenesis. Science 278: 1809-1812.

Simmons, D.M., J.W. Voss, H.A. Ingraham, J.M. Holloway, R.S. Broide, M.G. Rosenfeld, and L.W. Swanson, 1990. Pituitary cell phenotypes involve cell-specific Pit-1 mRNA translation and synergistic interactions with other classes of transcription factors. Genes \& Dev. 4: 695-711.

Sornson, M., W. Wu, J. Dasen, S. Flynn, D. Norman, S. O'Connell, I. Gukovsky, C. Carriere, A. Ryan, A. Miller, L. Zuo, A. Gleiberman, B. Andersen, W. Beamer, and M. Rosenfeld. 1996. Pituitary lineage determination by the Prophet of Pit-1 homeodomain factor defective in Ames dwarfism. Nature 384: 327-333.

Spemann, H. 1938. Embryonic development and induction. Yale University Press, N ew Haven, CT.

Stark, K., S. Vainio, G. Vassileva, and A.P. McMahon. 1994. Epithelial transformation of metanephric mesenchyme in the devel oping kidney regulated by Wnt4. Nature 372: 679683.

Steger, D.J., J.H. Hecht, and P.L. Mellon. 1994. GATA-binding proteins regulate the human gonadotropin alpha-subunit gene in the placenta and pituitary gland. Mol. Cell Biol.
14: 5592-5602.

Suzuki, A., R. Thies, N. Yamaji, J. Song, J. Wozney, K. Murakami, and N. Ueno. 1994. A truncated bone morhogenetic protein receptor affects dorsal-ventral patterning in the early Xenopus embryo. Proc. Natl. Acad. Sci. 91: 10255-10259.

Szeto, D.P., A.K. Ryan, S.M. O'Connell, and M.G. Rosenfeld. 1996. P-OTX: A Pit-1 interacting homeodomain factor expressed during anterior pituitary gland development. Proc. Natl. Acad. Sci. 93: 7706-7710.

Tabin, C. 1995. The initiation of the limb bud: Growth factors, Hox genes, and retinoids. Cell 80: 671-674.

Tanabe, Y. and T.M. Jessell. 1996. Diversity and pattern in the developing spinal cord. Science 274: 1115-1123.

Theslaff, I. and P. Sharpe. 1997. Signalling networks regulating dental development. Mech. Dev. 67: 111-123.

Thomas, P.Q., B.V. Johnson, J. Rathjen, and P.D. Rathjen. 1995. Sequence, genomic organization, and expression of the novel homeobox gene Hesx1. J. Biol. Chem. 270: 3869-3875.

Thor, S., J. Ericson, T. Brännström, and T. Edlund. 1991. The homeodomain LIM protein Isl-1 is expressed in subsets of neurons and endocrine cells in the adult rat. Neuron 7: 881889.

Treier, M. and M. Rosenfeld. 1996. The hypothal amic-pituitary axis: Co-development of two organs. Curr. O pin. Cell. Biol. 8: 833-843.

Vainio, S., I. Karavanova, A. Jowett, and I. Thesl eff. 1993. Identification of BM P-4 as a signal mediating secondary induction between epithelial and mesenchymal tissues during early tooth development. Cell 75: 45-58.

Voss, J.W. and M.G. Rosenfeld. 1992. Anterior pituitary development: Short tales from dwarf mice. Cell 70: 527-530.

Walther, C. and P. Gruss. 1991. Pax-6, amurine paired box gene, is expressed in the developing CNS. Development 113: 1435-1449.

Winnier, G., M. Blessing, P.A. Labosky, and B.L. Hogan. 1995. Bone morphogenetic protein-4 is required for mesoderm formation and patterning in the mouse. Genes \& Dev. 9: 21052116.

Woloshin, P., K. Song, C. Degnin, A. Killary, D. Goldhammer, D. Sassoon, and M. Thayer. 1995. MSX1 inhibits myoD expression in fibroblast 10T $1 / 2$ hybrids. Cell 82: 611-620.

Zannini, M., V. A vantaggiato, E. Biffal i, M .I. Arnone, K. Sato, M. Pischetola, B.A. Taylor, S.J. Phillips, A. Simeone, and R. Di Lauro. 1997. TTF-2, a new forkhead protein, shows a temporal expression in the developing thyroid which is consistent with a role in controlling the onset of differentiation. EMBO J. 16: 3185-3197.

Zhadanov, A.B., S. Bertuzzi, M. Taira, I.B. Dawid, and H. Westphal. 1995. Expression pattern of the murine LIM class homeobox gene Lhx3 in subsets of neural and neuroendocrine tissues. Dev. Dyn. 202: 354-364.

Zhang, H. and A. Bradley. 1996. Mice deficient for BM P2 are nonviable and have defects in amnion/chorion and cardiac development. Development 122: 2977-2986.

Zimmerman, L., J. De Jesus-Escobar, and R. Harland. 1996. The Spemann organizer signal noggin binds and inactivates bone morphogenetic protein 4. Cell 86: 599-606. 


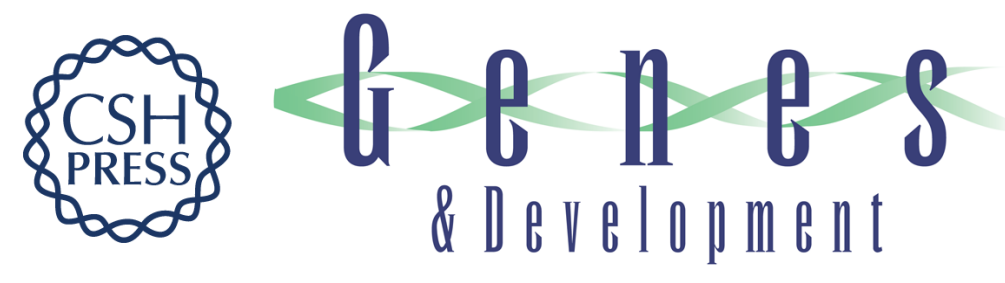

\section{Multistep signaling requirements for pituitary organogenesis in vivo}

Mathias Treier, Anatoli S. Gleiberman, Shawn M. O'Connell, et al.

Genes Dev. 1998, 12:

Access the most recent version at doi:10.1101/gad.12.11.1691

References This article cites 59 articles, 28 of which can be accessed free at: http://genesdev.cshlp.org/content/12/11/1691.full.html\#ref-list-1

License

Email Alerting Receive free email alerts when new articles cite this article - sign up in the box at the top Service right corner of the article or click here.

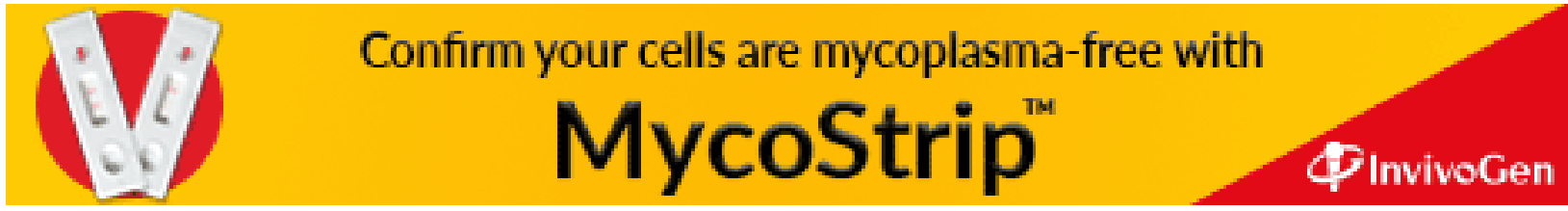

